\title{
Performance Evaluation of Power Operated Medicinal Nut Sheller for Ritha Nuts (Sapindus mukorossi)
}

\author{
R.A. Bangale*, Anamika Jha, P.A. Turbatmath and R.V. Sanglikar
}

Dr. A. S. College of Agril. Engineering, Mahatma PhuleKrishiVidyapeeth, Rahuri DistAhmednagar, Maharashtra, India

*Corresponding author

\begin{tabular}{|c|}
\hline Keywords \\
\hline $\begin{array}{l}\text { Ritha, Sapindus } \\
\text { mukorossi, Nut } \\
\text { sheller, Shelling } \\
\text { efficiency, Shear }\end{array}$ \\
\hline Article Info \\
\hline $\begin{array}{l}\text { Accepted: } \\
18 \text { April } 2018 \\
\text { Available Online: } \\
\text { 10 May } 2018\end{array}$ \\
\hline
\end{tabular}

\section{Introduction}

Sapindus mukorassi, is one of the oldest cultivated medicinal plants in the world. In fact Botanist traced it to the period of the Vedas about 5000 years ago. It is a medium sized deciduous tree growing wild in South India. Sapindus mukorassi belongs to the family Sapindaceae, rich in saponins. Sapindus grows at warm temperate and tropical regions (Rao et al., 2012). Spindus mukorossi is used in Ayurvedic medicines to remove tan and freckles from the skin. It cleanses the skin of oily secretion and is even used as a cleanser for washing hair as it forms a rich, natural lather. Also it is widely used as a detergent for the shawls and silks since ancient times (Choudhary et al., 2012). Ritha has been put to use in cosmetics, detergents and several other products. However, modern scientific medical research has investigated the use of soapnuts in treating migraines. It is traditionally used for removing lice from the sculp. Fruits are of considerable importance 
for their medical value which can treat many diseases like excessive salivation, pimples, epilepsy, eczema and psoriasis. The powdered seeds are employed in the treatment of dental caries, arthritis, common colds, constipation and nausea (Sabu et al., 2009).

Shelling of these medicinal nuts is a very difficult job. Presently shelling of medicinal nuts like ritha, hirads etc. is done manually by using hammer, wooden mallets, brick or stone. This process is time consuming and labour intensive. Also these conventional methods result in serious injury to human fingers coupled with low output (Nkakini, 2007).

Also some research is being done on handle operated shelling machines. Thus to avoid such injuries, make the process cheap and effective and also to reduce the time consumption a power operated medicinal nut sheller was developed at Department Of Farm Machinery and Power Engineering, Dr. Annasaheb Shinde College of Agricultural Engineering, Rahuri (Maharashtra, India).

\section{Materials and Methods}

\section{Power operated medicinal nut sheller}

On the basis of engineering properties of the ritha nuts (size, shape, thickness of shell, shell ratio and force required to break) as well as using the principle of shear, a power operated medicinal nut Sheller was designed and developed (Fig. 1).

The machine consists of five functional components i. e. main frame, feeding unit, shelling unit, power transmission unit and discharging unit. Shelling unit is the heart of the machine. Shelling unit consists of two rollers made up of white drawn bar. On these rollers, there are six grooves. The rollers are driven by meshing gears. These two gears rotate the rollers in counter direction.

\section{Operation of the power operated medicinal nut sheller}

The medicinal nuts are put in the feeding hopper manually. The rollers are then rotated by the belt drive in counter direction; the nuts pass automatically into two rotating rollers by gravity force. Nuts are crushed due to roller rotates in counter direction. Grooves on rollers help to hold the nuts till they are crushed.

After crushing the crushed nuts along with the seeds are collected in the tray and then the seeds are separated manually.

\section{Performance of the sheller}

The performance of developed power operated medicinal nut sheller was conducted for three different moisture contents to obtain the capacity, shelling efficiency and damaged seeds.

\section{Capacity of machine}

Capacity of machine was calculated by using following formula

$$
\text { Capacity of machine }=\frac{\text { Wt of nuts fed,kg }}{\text { Time required for shelling, h }}
$$

\section{Shelling efficiency}

The percent shelled nuts was calculated by using following formula

Percent shelled nuts $=\frac{\text { Qty of shelled nuts obtained from outlet } \mathrm{kg}}{\text { Total output } \mathrm{kg}} \times 100$

\section{Damaged seeds}

The percent broken seed was calculated by using following formula

Percent broken seed $=\frac{\text { Qty of broken seeds obtained from outletkg }}{\text { Total seed obtained from outlet } k g} \times 100$ 


\section{Results and Discussion}

The performance of power operated medicinal nut sheller was conducted at Workshop Technology Laboratory, Dr. A. S. College of Agriculture Engineering, MPKV, Rahuri. The tests were analyzed to determine the capacity of machine, shelling percentage of nuts and broken percentage of seeds. The results of tests are given in Table 1.

\section{All data are average of 3 replications}

\section{Effect of moisture content on shelling efficiency}

The result for the performance tests analysis shows that the moisture content of ritha nuts significantly affected the shelling efficiency at 5 per cent level of significance. The effect of moisture content on shelling efficiency is shown in the figure 6. From the figure, it can be seen that the shelling efficiency decreased with increase in moisture content. The maximum shelling efficiency of 86.25 per cent was observed at 6.4 per cent moisture content (w. b.).

Almost similar results were found in the study by Sharma et al., (2013) for Tung fruits in which they recorded $52.24 \%$ recovery of whole seeds and machine efficiency of $74.63 \%$ were recorded at fruit moisture content of $8.65 \%$ (d.b.).

Omoruyi and Ugwu (2013) have reported that cracking efficiency of palm nuts was highest at 9\% (db) moisture content and lowest at 13\% (db) moisture content. A similar decreasing trend in decortications efficiency in jatropha fruit was recorded by Pradhan et al., 2010.

The low shelling efficiency at high moisture content must be because wet fruits become more elastic than dry fruits and hence are not easily decorticated.

\section{Effect of moisture content on damaged seeds}

The result for the performance tests analysis shows that the moisture content of ritha nuts significantly affected the quantity of damaged seeds at 5 per cent level of significance (Fig. 5 ). The effect of moisture content on quantity of damaged seed is shown in the figure 7 . From the figure, it can be seen that the quantity of damaged seed decreased with increase in moisture content. The minimum seed damage of 5.76 per cent was observed at 11.23 per cent moisture content (w. b.). This may be because fruit become more brittle and susceptible to mechanical damage at low moisture content (Oluwel et al., 2007).

Similar trend was seen in the study by Omoruyi and Ugwu (2013) where in the mechanical damage was highest as well as recovery rate was lowest at $13 \%(\mathrm{db})$ moisture content. Pradhan et al., (2010) reported that percentage of broken seed decreased from $4.77 \%$ to $2.87 \%$ with increase in moisture content from 7.97 to $15.65 \%$ (d.b.). Similar increasing trend in percentage of partially shelled fruit and unshelled fruit has been reported for okra seed and bambara groundnut (Oluwel et al., 2007 and Khushwaha et al., 2005).

\section{Effect of moisture content on capacity of machine}

The result for the performance tests analysis shows that the moisture content of ritha nuts significantly affected the capacity of the machine at 5 per cent level of significance. The effect of moisture content on Capacity of machine is shown in the figure 6. From the figure, it can be seen that the Capacity of machine decreased with increase in moisture content. The maximum capacity of 200.93 $\mathrm{kgh}^{-1}$ was observed at 6.4 per cent moisture content (w. b.). 
Fig.1 Power operated medicinal nut sheller

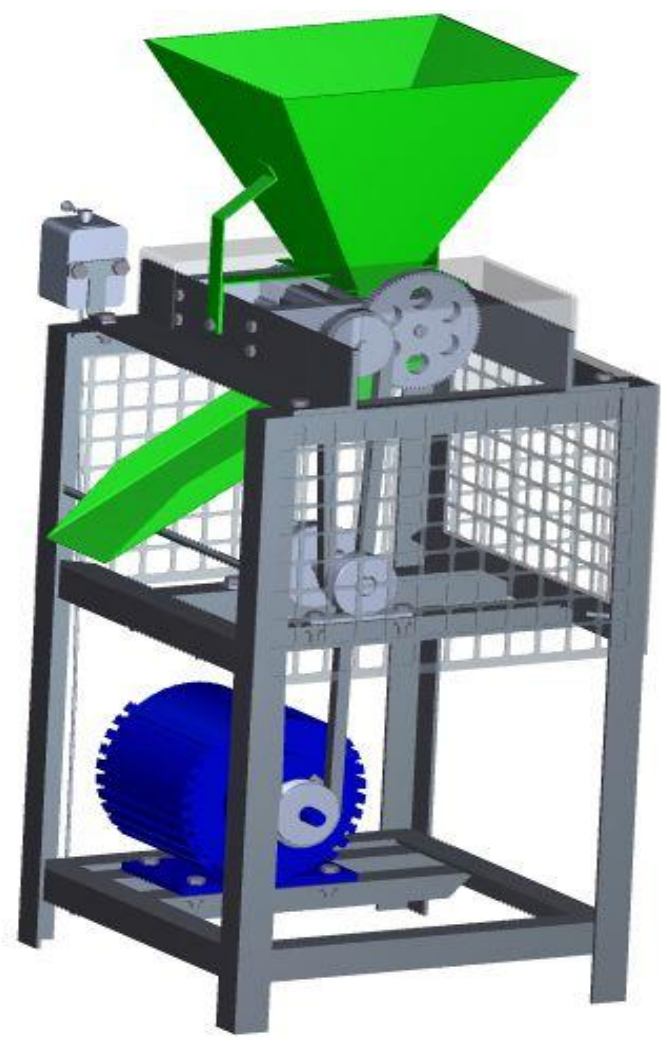

Fig.2 Ritha Nuts

Fig.3 Shelled Ritha

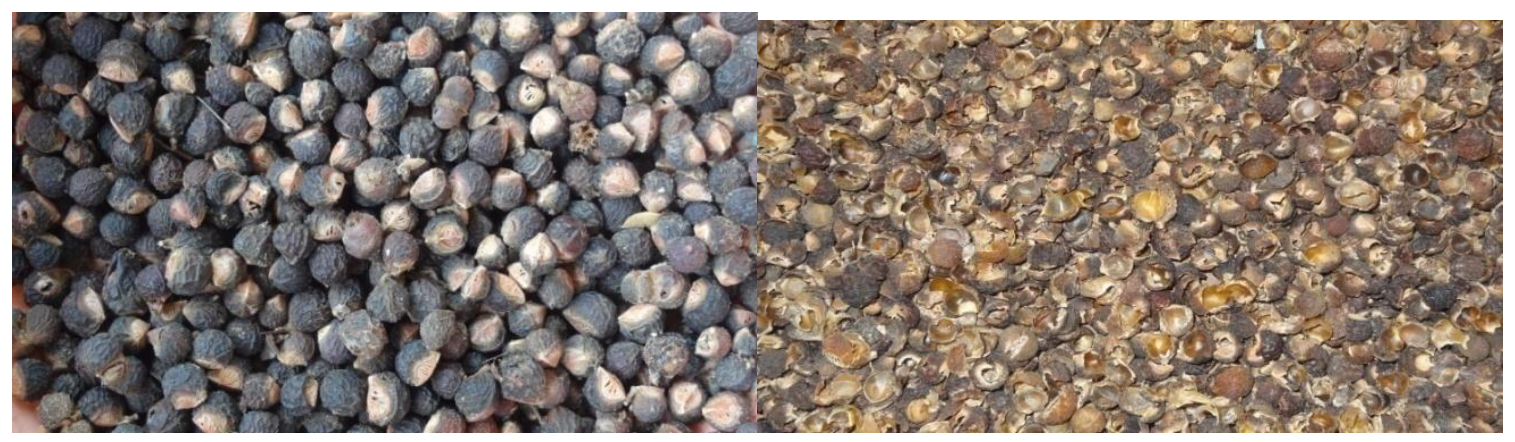

Fig.4 Shelled Ritha seeds

Fig.5 Damaged Ritha seeds

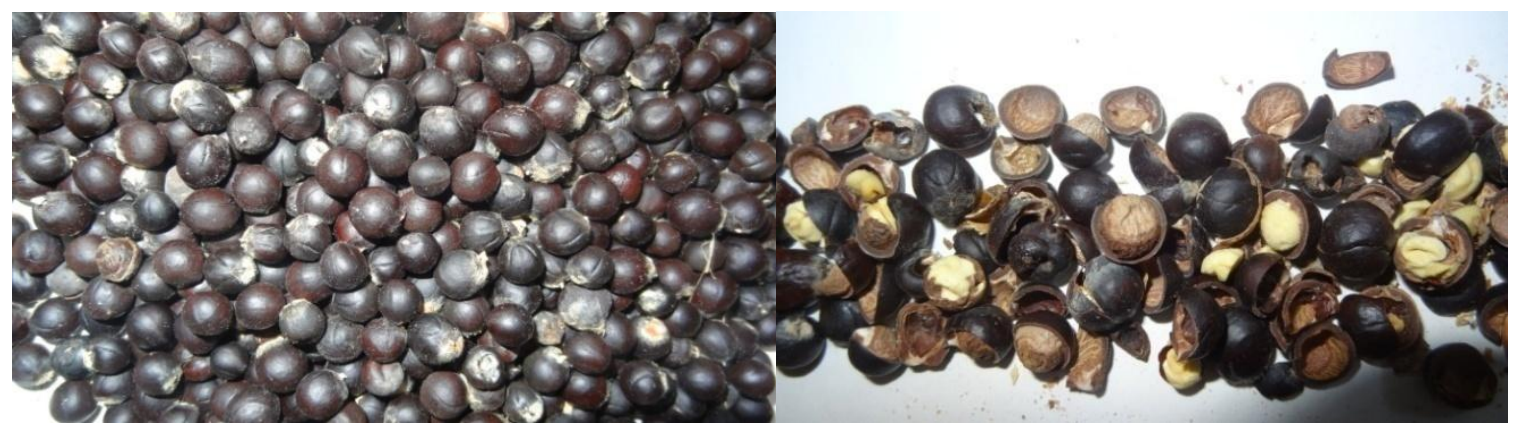


Fig.6 Effect of moisture content on shelling efficiency of Ritha Nuts

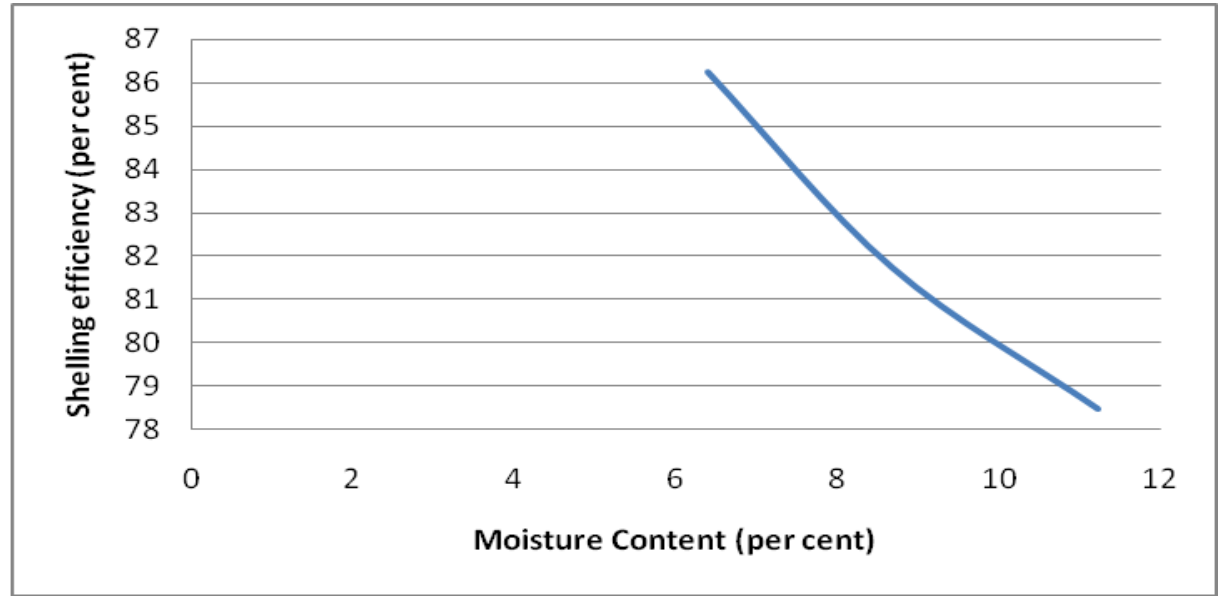

Fig.7 Effect of moisture content on damaged seeds

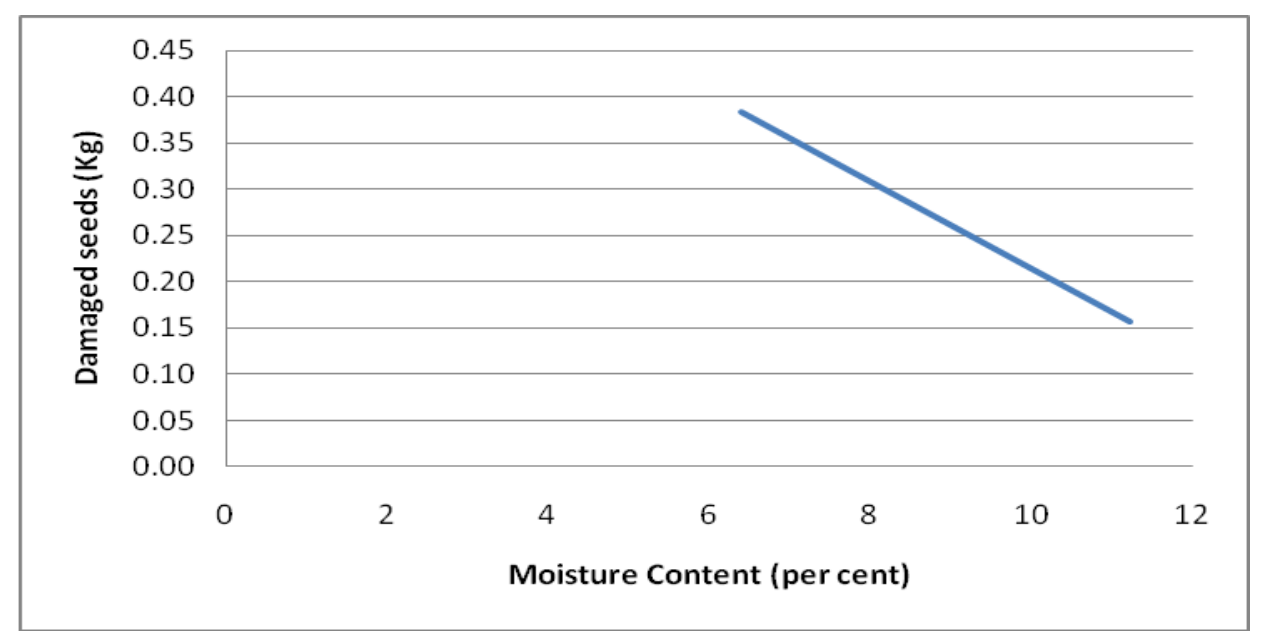

Fig.8 Effect of moisture content on capacity of machine

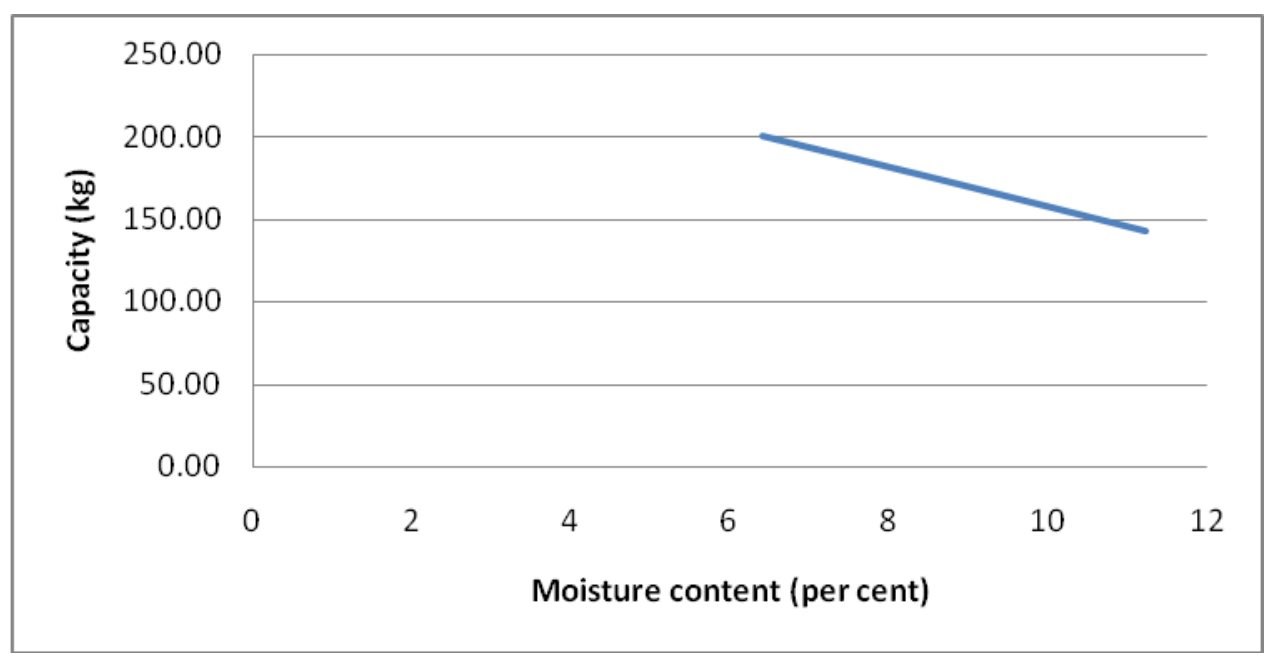


Table.1 Observations of power operated medicinal nut sheller for Ritha

\begin{tabular}{|l|c|c|c|}
\hline \multicolumn{1}{|c|}{ Particulars } & \multicolumn{3}{|c|}{ Moisture content (per cent) } \\
\hline Total weight of nuts fed, $\mathbf{k g}$ & $\mathbf{6 . 4 0}$ & $\mathbf{8 . 6 7}$ & $\mathbf{1 1 . 2 3}$ \\
\hline Total weight at outlet, $\mathbf{~ k g}$ & 12.60 & 14.56 & 14.33 \\
\hline Shelled nuts, kg & 12.35 & 14.51 & 13.47 \\
\hline Whole seed, kg & 7.60 & 7.69 & 7.70 \\
\hline Damaged seed, kg & 2.67 & 3.89 & 2.70 \\
\hline Unshelled nuts, kg & 0.38 & 0.27 & 0.16 \\
\hline Output, per cent & 1.71 & 2.64 & 2.91 \\
\hline Shelling efficiency, per cent & 98.00 & 99.63 & 93.96 \\
\hline Damaged seeds, per cent & 86.25 & 81.75 & 78.47 \\
\hline Capacity of machine, kgh $^{-1}$ & 14.32 & 6.69 & 5.76 \\
\hline
\end{tabular}

In study of cracking palm nut by Omoruyi and Ugwu (2013) percentage losses of the machine was highest using moisture content of $13 \%$ (db). Pradhan et al., (2010) have stated in their study that the best set of conditions under which the decorticator can be operated is at fruit moisture content of $7.97 \%$ d.b. at which maximum whole seeds of $67.94 \%$ can be achieved and machine efficiency of $90.96 \%$ can be obtained. In the same study they found that with increase in moisture content, efficiency of machine decrease because highest efficiency of $90.96 \%$ was found at $7.97 \%$ (d.b) while lowest of $73.25 \%$ at $15.65 \%$ (d.b.) moisture content. At par with our study was found the study by Adewumi and Fatusin (2006) where efficiency of machine was $85-100 \%$ for cocoa pod using an impact-type hand-operated cocoa pod breaker.

The efficiency of the machine decrease because at high moisture content, the seed coats or shells were stick resulting in a high force of friction to separate the shell from seeds. But at lower moisture content and at a optimum concave clearance, the fruits were less sticky and get required force to split and therefore were able to separate much more easily.
Performance evaluation of power operated medicinal nut sheller for ritha nuts was done to see the effect of moisture content on several performance parameters. The results showed that moisture content had a significant effect on shelling efficiency, damaged seed and the capacity of machine. The nut sheller works more efficiently as the moisture content of the fruit decreases. The shelling efficiency of the machine decreases with increase in fruit moisture content, while percentages of damaged seed decreased with increase in moisture content. The best moisture content for ritha nut shelling was found at moisture content of $6.4 \%$ (w.b.). It is a power operated machine thus enables timely operations and more production per unit time enhancing the business ritha nut for farmers. Due to the commercial demand of ritha nut farmers can be benefited by the use of this sheller and it can also be used for several other fruits and nuts

\section{References}

Adewumi BA, Fatusin AB.2006. Design, fabrication and testing of an impacttype hand-operated cocoa pod breaker. In: Agricultural engineering 
international: the CIGR E journal; VIII: $1-12$.

Bangale R. A., P. A. Turbatmath, R. V. Sanglikar, V. D. Deshmukh, J. S. Deshpande and M. R. Bedis. 2015. Development of power operated medicinal nut sheller. International $\mathrm{J}$. Agric. Engg., 8 (2):206-209

Choudhary G.P. 2012. Immunomodulatory activity of alcoholic extract of Terminalia belerica Linn. in mice Der Pharmacia Lettre, 2012, 4 (2):414-417.

Ibrahim, M. G., Shehu, A. A., Dauda, S.M. and Ahmad, D., 2016, Design, fabrication and testing of shea nut shelling machine. International Food Research Journal 23(Suppl): S71 - S79

Khuswaha, HL, Srivastava AP, Singh H.2005. Development and performance evaluation of okra seed extractor. In: Agricultural engineering international: the CIGR Ejournal; VII: 1-13.

Nkakini SO, Ayotamuno MJ, Maeba GPD, Ogaji SOT, Probert SD.2007. Manually powered continuous-flow maize-sheller. Appl Energy; 84: 1175-86.

Oluwole F, Abdulrahim A, Olalere R.2007. Evaluation of some centrifugal impaction devices for shelling bambra groundnut. Agr Eng Int: CIGR EJ; IX.
Omoruyi A.1, Ugwu K. C.2., 2013. Optimization and Performance Evaluation of Palm Nut Cracking Machine International Journal of Science and Research (IJSR). 23197064 Index Copernicus Value 6.14 |

Pradhan, R.C., S.N. Naik, N. Bhatnagar, V.K. Vijay, 2010. Design, development and testing of hand-operated decorticator for Jatropha fruit Applied Energy 87. 762768.

Rao, N.K. and S. Nammi. 2006. Antidiabetic and renoprotective effects of the chloroform extract of Terminalia chebula Retz. Seeds in streptozotocininduced diabetic rats, BMC Complement Altern Med.2006; 6:17.

Sabu M.C. and Ramadasan Kuttan. 2009. Antidiabetic and Anti oxidant activity of Terminalia belerica. Roxb, Indian Journal of Experimental Biology, 2009; 47: 270-275.

Sharmaa, V., R.C. Pradhan, S.N. Naika, N. Bhatnagar, Subedar Singh, 2013. Evaluation of a centrifugal impactiontype decorticator for shelling tung fruits Industrial Crops and Products 43 126131

\section{How to cite this article:}

Bangale, R.A., Anamika Jha, P.A. Turbatmath and Sanglikar, R.V. 2018. Performance Evaluation of Power Operated Medicinal Nut Sheller for Ritha Nuts (Sapindus mukorossi). Int.J.Curr.Microbiol.App.Sci. 7(05): 2195-2201. doi: https://doi.org/10.20546/ijcmas.2018.705.256 